\title{
Convergence of Economic Growth in Russian Megacities
}

Submitted 20/07/19, 1st revision 28/08/19, 2nd revision 18/09/19, accepted 27/11/19

\author{
Belova T.A. ${ }^{1}$, Prudnikov V.B. ${ }^{2}$, Abzalilova L.R. ${ }^{3}$, Bakhitova R.Kh. ${ }^{4}$
}

\begin{abstract}
:
Purpose: The article presents the results of an empirical analysis of the economic growth of Russian cities with a population of over 1 million people (megacities).

Design/Methodology/Approach: The analyzed indicator is the city product calculated according to the UN methodology for the period from 2010 to 2016. The paper analyses the process of $\beta$ - and $\sigma$-convergence across Russian megacities using methods of spatial econometrics in addition to the traditional $\beta$-convergence techniques from the neoclassical theoretical framework.

Findings: The dynamics of the coefficient of variation confirmed the presence of $\sigma$ convergence in city product. Empirically, positive spatial autocorrelation has been confirmed. Beta-convergence for Russian megacities is found to be significant and the spatial location of megacities significantly affects $\beta$-convergence. Control factors such as fixed capital investment per capita in 2010, average retail volume per capita in 2010, average annual number of employees of enterprises and organizations in 2010 and the dummy variable introduced for "federal cities" Moscow and St. Petersburg are all found to have positive and statistically significant impact on economic growth.

Practical Implications: Policymakers may take the results into account under the planning of economical strategies for megacities and regions in Russia in order to facilitate the regional economic growth and the speed of convergence.

Originality/Value: The main contribution of the study is the consideration of the economical growth for the megacities and not for the regions as it often used to be the case in similar studies. The important finding is that megacities ' economies do converge and the influence of control factors is pronounced.
\end{abstract}

Keywords: Russian megacities, economic growth, convergence, spatial autocorrelation.

JEL Code: C01, C21,F43,F62, F63, O47.

Paper type: Research article: Spatial Economics.

${ }^{1}$ Teaching Professor of the Department of "Mathematical Methods in Economics", Bashkir State University,k.t.a.1991.1991 @ mail.ru

${ }^{2}$ Associate Professor of the Department of "Mathematical Methods in Economics", Bashkir

StateUniversity,prudnikov.bgu@mail.ru

${ }^{3}$ Associate Professor of the Department of "Mathematical Methods in Economics", Bashkir

State University, abzalilova.liya@gmail.com

${ }^{4}$ Professor of the Department of "Mathematical Methods in Economics", Bashkir State

University, bakhitovarh@mail.ru 


\section{Introduction}

The Russian Federation is the largest country in the planet. It is not surprising that in studying the country's economy, researchers over the past ten years have sought to take into account the territorial heterogeneity of the regions and their interrelationships. In early studies (Ahrend, 2002; Berkowitz and Dejong, 2003), the geographical factor was introduced into the models as a control variable denoting, for example, the distance separating the region from Moscow, common borders with third countries, access to the open sea or geographical longitude, or where the capital of the region is located.

Later on, the methods of spatial econometrics began to be used to study the spatial effects of the interaction of Russian regions. Among the early studies on the analysis of unconditional and conditional convergence of the Russian regions, we can note the important work by Lugovoy (2007) as well as the article by Solanko (2003). It has been shown that the regions converge to one of two stable states depending on the intellectual potential, the share of industry, agriculture in the economy and other factors. The variable reflecting the distance from Moscow turned out to be insignificant. Similar studies were later carried out by Buchellato (2007), Vakulenko (2013), Ivanova (2014), Kolomak (2010), Balash (2013), Zverev and Kolomak (2010), Glushchenko (2012) and others.

All of the above works are based on the theory of new economic geography, and test the presence of convergence of economic growth in Russian regions. The gross regional product per capita or the average per capita income of the population of a region was often taken as the indicator of the level of economic development. The authors test the hypothesis of the presence of spatial autocorrelation of the indicator, using different types of spatial weights matrices and additional control factors. In particular, Vakulenko (2013) investigated the impact of interregional migration on economic growth.

The closest to this study (in terms of the methods used) is the work by Lugovoy et al. (2007), where the models of unconditional, minimal conditional and conditional betaconvergence (Fingleton, 2003) for the regions of Russia are considered. The analyzed indicator is the gross regional product per capita. The obtained negative external spatial effects of the dynamics of economic development of regions are interpreted by the authors as the effect of competition during inter-regional interactions. Similar results were obtained by Zverev and Kolomak (2010). The main economic indicators are the nominal per capita gross regional product and nominal budget revenues per capita for the period 1995-2007.

In international sources we find that convergence models are built mainly on panel data (Celbis, Wong and Guznajeva, 2018; Royuela and Garcia, 2015). The first paper provides the analysis of 118 regions of Belarus for the period 2005-2014, where their spatial clustering is revealed. It was shown that after the formation of the Eurasian 
Union, there was a slowdown in economic convergence and increased competition among the regions. The second paper presents the analysis of the economic and social convergence of the regions of Colombia in the period 1975-2005. Although convergence is statistically absent in terms of regional GDP, it takes place in a number of social indicators (life expectancy, infant mortality, education coverage, crime rates).

Nevertheless, Russian researchers mainly rely on cross-sectional data. In fact, crosssectional models better describe how persistent cross-sectional differences in economic inequality affect long-term economic growth. This is more important when describing uneven growth. Fixed-effect panel models, however, tend to better capture how time series dynamics affect economic trends.

The present work uses cross-sectional data. The main purpose was to study not the regional convergence, but the convergence of megacities, given the increasing role of urban agglomerations in the Russian economy. For the period from 2010 to 2018 , large centers of economic growth created $68 \%$ of the total growth of the gross regional product, yet represents only $40 \%$ of the population. According to the draft of Spatial Development Strategy of Russia until 2025, it is assumed that economic growth in general will be concentrated in a limited number of centers (agglomerations). Therefore, the interaction of the economies of megacities in the framework of the theory of new economic geography is important to study.

The paper is organized as follows. At the beginning, a brief description of the convergence models is given, the source data and the methods and models used for the analysis are described. We propose the results of a preliminary check of the values of the city product for the presence of spatial clustering for the megacities. Next, the models of the minimal conditional and conditional convergence are formulated in various specifications taking into account spatial effects, the choice of a matrix of spatial weights and convergence indicators. In the results section, the actual dynamics of the coefficient of variation of the city product is presented, as well as the results of the assessment, analysis and interpretation of models that meet the best information criteria. The last section contains the main findings.

\section{The Concept of Convergence and its Preliminary Testing}

The concept of unconditional $\beta$-convergence, first introduced by Solow (1956) and Swan (1956), is based on the assumption that in a steady state of equilibrium the economic growth rates of the territories are constant on the growth trajectory and the speed of approaching a given trajectory for a specific territory is determined by the current value of the indicator, namely, the poorer the territory, the higher its economic growth rate.

In models of minimal conditional and conditional $\beta$-convergence, it is assumed that different groups of territories may have different trajectories of sustainable growth. 
As a result, additional terms are introduced into the model that correspond to different stable states. The consideration of such models with regard to spatial interactions is of particular interest. It is assumed that the closer the territories are to each other, the stronger the relationship between them. Interconnection refers to the full range of potential impact of territories on each other: labor migration and transfer of production, trade, social relations, information, and intellectual exchange. For the formalization of spatial relationships, spatial weights matrices are used (see the Methods and models section).

The model of minimal conditional $\beta$-convergence assumes that the growth trajectories of various groups of territories are determined, among other factors, by indicators of the economic development of neighboring territories (both at their average economic growth rates and at initial levels). The most general model of conditional $\beta$ convergence describes the rate of economic growth of territories, taking into account additional exogenous control factors, and in the Durbin specification, also includes spatial lags for such factors.

According to Quah (1993) $\beta$-convergence is a necessary condition for $\sigma$-convergence. If $\beta$-convergence characterizes the process of convergence of a trajectory of economic development of a territory to a trajectory of stable equilibrium, then $\sigma$-convergence describes the dynamics of the inequality of trajectories themselves. In fact, measuring the spread, $\sigma$-convergence can be determined by the dispersion, coefficient of variation, Gini coefficient or some other measures. The calculation of the dynamics of these indicators would allow us to estimate the possibility of convergence.

\section{Data}

In the present study, Russian megacities were considered as territories. According to the official data of the Federal State Statistics Service, as of January 12019 , the population of 16 cities exceeds 1 million people. While studying convergence for regions, the indicator of the gross regional product is traditionally used as the dependent variable. However, the choice of the type of dependent variable in the case of megacities is not that trivial. In fact, in the Russian Federation there is not any generally accepted method of calculating the gross domestic product indicator of municipalities. Researchers apply various techniques (Krinichanskii, Bezrukov and Lavrent'ev, 2015; Pulyaevskaya, 2015).

For this study, we consider that it is most appropriate to use the city product indicator proposed by the UN for monitoring the dynamics of urban development (Urban Indicators Guideline, 2009). The indicator was calculated according to method A of the methodology based on the following official statistics of the Federal State Statistics Service for megacities: the gross regional product of the region, of which the megacity is the capital, the average number of employees of organizations (region and megacity), the average monthly wage of employees of organizations (region and megacity). Additional control factors, in accordance with the methodology of the 
expanded production function are the following: investment in fixed capital from all sources of financing per capita, the average annual number of employees of enterprises and organizations (without external part-time workers), and the volume of retail trade per capita. An index of the physical volume of the gross regional product was used as a deflator for the city product, and for investment in fixed assets an index of investments in fixed capital was used as a deflator.

All baseline data used in this study were calculated by the Federal State Statistics Service and obtained from the organization's official website (Federal State Statistics Service, 2018). We used the data for 7 years from 2010 to 2016, due to that the data for 2017 will only published at the end of 2019.

\section{Methods and Models}

To test the hypothesis about the presence of $\beta$-convergence between Russian megacities, an econometric analysis was carried out within the framework of minimal conditional and conditional models of $\beta$-convergence. To check the hypothesis of spatial autocorrelation global Moran's and Geary's indices were used. The test results are shown in Table 1. The null hypothesis of the absence of spatial autocorrelation is rejected at the $5 \%$ significance level.

Table 1. Moran and Geary autocorrelation coefficients for the logarithm of the city product growth rate per capita (2016)

\begin{tabular}{|c|l|l|l|}
\hline Index & Value & t-st. & Prob. \\
\hline$I$ & 0.200 & 2.149 & 0.032 \\
\hline$C$ & 0.559 & 2.986 & 0.003 \\
\hline
\end{tabular}

The Moran's scatterplot also showed the spatial clustering of megacities by the logarithm of the city product growth rate per capita. In the first quadrant (the economy is growing rapidly, surrounded by the same "fast-growing" cities) there are only two cities, so-called "federal cities" Moscow and St. Petersburg. Note, that Balash (2013) and Lugovoi et al. (2007) obtained a similar result.

Thus, in general, it is possible to speak about the presence of significant positive spatial dependence in the economic development of megacities, that should be taken into account when conducting empirical studies. Depending on the specification of spatial interactions, three models of minimal conditional $\beta$-convergence were considered, given below in vector form:

- Spatial autoregression model (SAR):

$$
\left(\frac{1}{T}\right) \ln \left(\frac{y_{T}}{y_{0}}\right)=\alpha+\beta \ln \left(y_{0}\right)+\rho W \ln \left(\frac{y_{T}}{y_{0}}\right)+\varepsilon, \varepsilon \sim N\left(0, \sigma^{2} I\right),
$$


where $\ln \left(y_{0}\right)-$ logarithm of city product per capita in $2010, W-$ spatial weights matrix, $\rho$-spatial lag parameter;

- Spatial error model (SEM):

$$
\begin{gathered}
\left(\frac{1}{T}\right) \ln \left(\frac{y_{T}}{y_{0}}\right)=\alpha+\beta \ln \left(y_{0}\right)+u \\
u=\lambda W u+\varepsilon, \varepsilon \sim N\left(0, \sigma^{2} I\right),
\end{gathered}
$$

where $\lambda$ - coefficient for autoregressive parrameter for error term;

- SAC model, that takes into account both spatial autocorrelation in dependent variable andspatial disturbances in error term:

$$
\begin{aligned}
& \left(\frac{1}{T}\right) \ln \left(\frac{y_{T}}{y_{0}}\right)=\alpha+\beta \ln \left(y_{0}\right)+\rho W \ln \left(\frac{y_{T}}{y_{0}}\right)+u \\
& u=\lambda W u+\varepsilon, \varepsilon \sim N\left(0, \sigma^{2} I\right) .
\end{aligned}
$$

Models of conditional convergence also take into account the impact on the rate of economic growth of control exogenous factors. The selection of factors was carried out on the basis of the methodology of the extended production function, taking into account the specifics of the megacities.The following indicators were included as controls:

1) the parameter of development of the economies of megacities in the form of a logarithm of investments in fixed capital from all sources of financing per capita;

2) the parameter of labor resources in the form of the logarithm of the average annual number of employees of enterprises and organizations (without external part-time workers and employees of unscheduled staff);

3 ) the parameter of the infrastructure of the city in the form of the logarithm of retail volume per capita;

4) the parameter of geographical heterogeneity of the Russian Federation: a dummy variable that highlights the special role of "federal cities", where a large number of economic agentsis concentrated.

To increase the credibility of the study all indicators were deflated, and indicators calculated at current prices were converted to comparable fixed prices. The index of the physical volume of the gross regional product was used as a deflator (in comparable prices; as a percentage of the previous year) for the city product andthe index of investments in fixed assets was used as a deflator for investments in fixed assets.

For conditional convergence we have studied four types of model specification:

- SAR: 


$$
\begin{aligned}
& \left(\frac{1}{T}\right) \ln \left(\frac{y_{T}}{y_{0}}\right)=\alpha+\beta \ln \left(y_{0}\right)+\rho W \ln \left(\frac{y_{T}}{y_{0}}\right)+\varphi_{1} \ln \left(\text { inv }_{0}\right)+ \\
& +\varphi_{2} \ln \left(\text { empl }_{0}\right)+\varphi_{3} \ln \left(\text { retail }_{0}\right)+\varphi_{4} F C+\varepsilon, \varepsilon \sim N\left(0, \sigma^{2} I\right),
\end{aligned}
$$

where $i n v_{0}$-value investment in fixed capital per capita in 2010, empl $l_{0}$-average annual number of employees of enterprises and organizations in 2010, retail $_{0}$ volume of retail trade per capita in $2010, F C$ is a dummy variable, equal to 1 for "federal cities"and 0 for other megacities, $\varphi_{1}, \ldots, \varphi_{4}-$ coefficients by the control variables;

- SEM:

$$
\begin{gathered}
\left(\frac{1}{T}\right) \ln \left(\frac{y_{T}}{y_{0}}\right)=\alpha+\beta \ln \left(y_{0}\right)+\varphi_{1} \ln \left(i n v_{0}\right)++\varphi_{2} \ln \left(\text { empl }_{0}\right)+ \\
\varphi_{3} \ln \left(\text { retail }_{0}\right)+\varphi_{4} F C+u, \\
u=\lambda W u+\varepsilon, \varepsilon \sim N\left(0, \sigma^{2} I\right),
\end{gathered}
$$

- SAC:

$$
\begin{gathered}
\left(\frac{1}{T}\right) \ln \left(\frac{y_{T}}{y_{0}}\right)=\alpha+\beta \ln \left(y_{0}\right)+\rho W \ln \left(\frac{y_{T}}{y_{0}}\right)+\varphi_{1} \ln \left(\text { inv }_{0}\right)+ \\
+\varphi_{2} \ln \left(\text { empl }_{0}\right)+\varphi_{3} \ln \left(\text { retail }_{0}\right)+\varphi_{4} F C+u, \\
u=\lambda W u+\varepsilon, \varepsilon \sim N\left(0, \sigma^{2} I\right),
\end{gathered}
$$

- SDM:

$$
\begin{aligned}
& \left(\frac{1}{T}\right) \ln \left(\frac{y_{T}}{y_{0}}\right)=\alpha+\beta \ln \left(y_{0}\right)+\rho W \ln \left(\frac{y_{T}}{y_{0}}\right)+\varphi_{1} \ln \left(i n v_{0}\right)+ \\
& +\varphi_{2} \ln \left(\text { empl }_{0}\right)+\varphi_{3} \ln \left(\text { retail }_{0}\right)+\varphi_{4} F C+\gamma_{1} W \ln \left(i n v_{0}\right)+ \\
& +\gamma_{2} W \ln \left(\text { empl }_{0}\right)+\gamma_{3} W \ln \left(\text { retail }_{0}\right)+\gamma_{4} W F C+\varepsilon, \varepsilon \sim N\left(0, \sigma^{2} I\right),
\end{aligned}
$$

where $\gamma_{1}, \ldots, \gamma_{4},-$ coefficients by the control variables characterizing their spatial influence.

A spatial model of Durbin (SDM) suggests a possible spatial impact on the rate of economic growth in a certain megacity values of the control factors of all the other cities. Estimating the minimum conditional and conditional $\beta$-convergence models using the least squares method leads to inconsistent parameter estimates due to the presence of the stochastic regressor $W \ln \left(\frac{y_{T}}{y_{0}}\right)$ (Anselin, 1988). For this reason, the maximum likelihood method was used for estimation.

\subsection{Spatial Weights Matrix}

In this study, we used a matrix of squares of inverse distances, the elements of which are calculated as follows: 


$$
w_{i, j}=\left\{\begin{array}{l}
0, i=j \\
\frac{1}{d_{i j}^{2}}, i \neq j
\end{array}\right.
$$

The advantage of using this type of matrix is that it takes into account the interrelationships of all megacities on each other. Estimates of $d_{i j}$ were calculated as the shortest distances between megacities by public autobans, as per information from the website of the AutoTransInfo transportation system.

\subsection{Convergence Indicators}

As indicators of the convergence process, following the works (Royuela, Garcia, 2015; (O. Lugovoy et al., 2007), the characteristics of the convergence speed $(\hat{b})$ the period of semi-convergence $(\widehat{h l})$ were used, calculated on the basis of the convergence speed, as follows from (12) and (13):

$$
\begin{aligned}
& \hat{b}=-\ln (1+T \hat{\beta}) / T, \\
& \widehat{h l}=\ln (2) / \hat{b},
\end{aligned}
$$

The period of semi-convergence is a period of time (in years) needed for a megacity to cover half the distance separating its economy from a steady state.

\section{Results}

\subsection{Sigma Convergence}

To assess the dynamics of changes in the inequality of the value of the city product and check for the presence of sigma-convergence, we used the coefficient of variation values. The calculated dynamics for the coefficient of variation of the city product per capita in megacities from 2009 to 2016 is presented in Table 2.

Table 2. The coefficient of variation of the city product per capita

\begin{tabular}{|l|l|l|l|l|l|l|l|}
\hline Year & 2010 & 2011 & 2012 & 2013 & 2014 & 2015 & 2016 \\
\hline CV & 0,407 & 0,41 & 0,409 & 0,414 & 0,393 & 0,38 & 0,373 \\
\hline
\end{tabular}

It shows that the coefficient of variation of the city product per capita follows a random path until 2013. However, since 2013 there has been a steady downward trend, indicating a possible $\sigma$-convergence. Thus, the reduction of economic inequality of cities (urban agglomerations) is currently continuing.

\subsection{Models of Minimal Conditional Beta-Convergence}

As shown in the Methods and models section, there is a spatial relationship between the growth rates of megacities. Therefore, the corresponding models of the minimal 
conditional $\beta$-convergence were evaluated according to equations (1)-(3), in the specifications of spatial autoregression (SAR), taking into account spatial error autocorrelation (SEM), and SAC. The evaluation results are shown in Table 3.

Table 3. Results of estimation of models of minimally conditional $\beta$-convergence

\begin{tabular}{|l|l|l|l|}
\hline $\begin{array}{l}\text { Log of the average city product growth } \\
\text { rate per capita } \\
(2010-2016)\end{array}$ & Specification & SEM & SAC \\
\cline { 2 - 4 } & SAR & & \\
\hline $\begin{array}{l}\text { Logarithm of city product per capita in } \\
2010\end{array}$ & $\begin{array}{l}-0.01109^{* *} \\
(-2.21)\end{array}$ & $\begin{array}{l}-0.0096^{*} \\
(-1.99)\end{array}$ & $\begin{array}{l}-0.01109^{* *} \\
(-2.21)\end{array}$ \\
\hline Constant & $\begin{array}{l}5.7778^{* * *} \\
(18.73)\end{array}$ & $\begin{array}{l}7.7356 \\
(1.31)\end{array}$ & $\begin{array}{l}5.8908 \\
(0.11)\end{array}$ \\
\hline Rho & $\begin{array}{l}0.31098^{* *} \\
(3.07)\end{array}$ & & $\begin{array}{l}0.31096^{* *} \\
(2.65)\end{array}$ \\
\hline lambda & & 0.26137 & 0.0192 \\
& & $(0.46)$ & $(0.46)$ \\
\hline Sigma (Variance) & $0.071262^{* * *}$ & $0.072902^{* * *}$ & $0.07126^{* * *}$ \\
& $(5.66)$ & $(5.66)$ & $(5.66)$ \\
\hline Convergence speed, $\%$ & 1.15 & 0.99 & 1.15 \\
\hline Semi-convergence, years & 60 & 70 & 60 \\
\hline Number of observation & 16 & 16 & 16 \\
\hline F-st. & $4.27 *$ & $3.48^{*}$ & $4.27 *$ \\
\hline R-squared & 0.2338 & 0.1989 & 0.2337 \\
\hline Adj R-squared & 0.2345 & 0.1989 & 0.2348 \\
\hline Akaike Information Criterion & 0.0065 & 5.2554 & 0.0231 \\
\hline Schwarz Criterion & 0.0072 & 5.7882 & 0.0255 \\
\hline
\end{tabular}

Note: $T$-statistics are presented in parentheses.

$*, * *, * * *$ correspond to the significance levels less than $0.10,0.05$ and 0.01 .

Based on the information criteria of Akaike and Schwarz, we conclude that the best specification for estimating the minimal conditional $\beta$-convergence model is the spatial autoregression model (SAR). In the SAR model, the coefficient of convergence is significant and has a negative value, which corresponds to theoretical assumptions about the presence of a negative correlation between economic growth rates and the current level of economic development. The hypothesis of the absence of a minimal conditional $\beta$-convergence (the sustainable growth paths of megacities differ only due to spatial clustering by the logarithms of the city product growth rate per capita) is rejected at the 5\% significance level. The estimated speed of convergence is $1.15 \%$ per year, which corresponds to a half-period of convergence equal to 60 years.

At the same time, the spatial lag coefficient in the SAR model $(\rho)$ is significant at the $5 \%$ level and positive, indicating the positive spatial autocorrelation between Russian megacities. This conclusion is consistent with the Moran scatterplot and Moran and Geary statistics calculated above. 
It should be noted that the initial level of the city product per capita and the endogenous spatial lag explain only about $23.38 \%$ of the variation of the logarithm of the city product growth rate per capita in this model. A rather low indicator of the explained variation indicates the possibility of the existence of other factors that take into account the specifics of particular megacities.

Thus, in order to increase the explanatory power of the models, it is necessary to consider specifications within the framework of conditional $\beta$-convergence, taking into account the control exogenous factors affecting the economic growth rates of megacities.

\subsection{Conditional Beta-Convergence Models}

To propose a system of indicators describing differences in economic development, the methodology of the extended production function was used, with the inclusion of exogenous factors in the model according to (4)-(8).

Table 5 presents the results of estimation of spatial models in the SAR, SEM, SAC and SDM specifications. Again, a matrix of squares of inverse distances was used as a spatial weights matrix. The choice between model specifications is based on the coefficient of determination, the information criteria of Akaike and Schwartz.

Table 5. Results of estimation of conditional $\beta$-convergence models

\begin{tabular}{|c|c|c|c|c|}
\hline \multirow{2}{*}{$\begin{array}{l}\text { Log of the average city } \\
\text { product growth rate per } \\
\text { capita (2010-2016) }\end{array}$} & \multicolumn{4}{|l|}{ Specification } \\
\hline & SAR & SEM & SAC & SDM \\
\hline $\begin{array}{l}\text { Logarithm of city } \\
\text { product per capita in } \\
2010\end{array}$ & $\begin{array}{l}-0.05289 * * * \\
(-3.36)\end{array}$ & $\begin{array}{l}-0.0529 * * * \\
(-3.36)\end{array}$ & $\begin{array}{l}-0.05289 * * * \\
(-3.36)\end{array}$ & $\begin{array}{l}-0.0601 * * * \\
(-3.68)\end{array}$ \\
\hline $\begin{array}{l}\text { Logarithm } \\
\text { investment in fixed } \\
\text { capital per capita in } \\
2010\end{array}$ & $\begin{array}{l}0.01611 * * \\
(2.1)\end{array}$ & $\begin{array}{l}0.01646 * * \\
(2.24)\end{array}$ & $\begin{array}{l}0.01612 * * \\
(2.1)\end{array}$ & $\begin{array}{l}0.0097 \\
(1.03)\end{array}$ \\
\hline $\begin{array}{l}\text { Logarithm of the } \\
\text { average annual number } \\
\text { of employees of } \\
\text { enterprises and } \\
\text { organizations in } 2010\end{array}$ & $\begin{array}{l}0.065399 * * * \\
(9.66)\end{array}$ & $\begin{array}{l}0.065455 * * * \\
(9.67)\end{array}$ & $\begin{array}{l}0.0653988 * * \\
* \\
(9.66)\end{array}$ & $\begin{array}{l}0.068308 * * \\
* \\
(10.37)\end{array}$ \\
\hline $\begin{array}{l}\text { Logarithm of retail } \\
\text { volume per capita in } \\
2010\end{array}$ & $\begin{array}{l}0.00907 * * \\
(2.11)\end{array}$ & $\begin{array}{l}0.0092442 * * \\
(2.23)\end{array}$ & $\begin{array}{l}0.00907 * * \\
(2.11)\end{array}$ & $\begin{array}{l}0.008818 * * \\
(2.26)\end{array}$ \\
\hline Dummy variable & $\begin{array}{l}0.096291 * * * \\
(7.11)\end{array}$ & $\begin{array}{l}0.094906 * * * \\
(9.19)\end{array}$ & $\begin{array}{l}0.0962907 * * \\
* \\
(7.11)\end{array}$ & $\begin{array}{l}0.09838^{* *} \\
(2.53)\end{array}$ \\
\hline
\end{tabular}




\begin{tabular}{|c|c|c|c|c|}
\hline Constant & $\begin{array}{l}4.391577 * * \\
(37.19)\end{array}$ & $\begin{array}{l}4.330256 \\
(1.62)\end{array}$ & $\begin{array}{l}4.521655 \\
(0.48)\end{array}$ & $\begin{array}{l}\text { 4.454807** } \\
* \\
(3.34)\end{array}$ \\
\hline Rho & $\begin{array}{l}0.1654 * * \\
(2.8)\end{array}$ & & $\begin{array}{l}0.1657 * * \\
(2.77)\end{array}$ & $\begin{array}{l}0.1614 * * \\
(2.44)\end{array}$ \\
\hline lambda & & $\begin{array}{l}0.0136124 \\
(0.2)\end{array}$ & $\begin{array}{l}-0.02877 \\
(0.1) \\
\end{array}$ & \\
\hline Sigma (Variance) & $\begin{array}{l}0.06261^{* * *} \\
(5.66)\end{array}$ & $\begin{array}{l}0.014866 * * * \\
(5.66)\end{array}$ & $\begin{array}{l}0.014855 * * * \\
(5.66)\end{array}$ & $\begin{array}{l}0.012419 * * \\
* \\
(5.66)\end{array}$ \\
\hline Convergence speed, $\%$ & 6.6051 & 6.611 & 6.605 & 7.8 \\
\hline $\begin{array}{l}\text { Semi-convergence, } \\
\text { years }\end{array}$ & 10 & 10 & 10 & 8.89 \\
\hline Number of observation & 16 & 16 & 16 & 16 \\
\hline F-st. & $58.14 * * *$ & $58.04 * * *$ & $58.14 * * *$ & $21.23 * * *$ \\
\hline R-squared & 0.9667 & 0.9667 & 0.9667 & 0.9770 \\
\hline Adj R-squared & 0.9547 & 0.9547 & 0.9547 & 0.9425 \\
\hline $\begin{array}{ll}\text { Akaike } & \text { Information } \\
\text { Criterion } & \end{array}$ & 0.0005 & 0.0078 & 0.0363 & 0.0016 \\
\hline Schwarz Criterion & 0.0006 & 0.0105 & 0.0484 & 0.0017 \\
\hline
\end{tabular}

Note: $T$-statistics are presented in parentheses.

$*, * *, * * *$ correspond to the significance levels less than 0.10, 0.05 and 0.01 .

Source: Authors' calculations.

Again, based on the information criteria, the SAR model is the best specification for estimating the conditional $\beta$-convergence model. It should also be noted, that the estimated coefficients, results on the rate of convergence, and the period of semiconvergence, are very close for all types of specification. After taking into account exogenous factors, the coefficient of determination increased significantly. The coefficient of convergence, as expected, is negative and statistically significant at the $1 \%$ significance level in the SAR model. It would take about 10 years for an average megacity to cover half the distance separating the city's economy from a steady state of growth, correspondingspeed of convergence is about $6.6 \%$ per year. Comparing these results with those of minimal conditional convergence modes, we find that the addition of these exogenous factors leads to a significant increase in the speed of convergence and the period of semi-convergence. Lugovoy et al. (2007) came to a similar conclusion. As in the model of minimal conditional $\beta$-convergence, the presence of positive spatial autocorrelation between megacities has been revealed.

The logarithm of the city product growth rate significantly depends on the initial level of the city's development for 2010, the logarithm of fixed capital investment per capita, the logarithm of average retail volume, and the logarithm of the average annual number of employees of enterprises and organizations. In addition, positive spatial autocorrelation (from logarithms of city product growth rates in other cities) is significant. The dummy variable for "federal cities" (Moscow and St. Petersburg) also 
turned out to be significant at least at the 5\% significance level in all specifications. Cities of federal significance economically influence the development of the economies of all other Russian mega cities. In general, the results indicate that a more developed infrastructure, population mobility, as well as a large stock of human capital lead to greater economic and geographical connectivity, and reduces the spatial barriers to the spread of economic growth.

\section{Conclusions and Discussion}

1. Based on the dynamics of the coefficient of variation in 2010-2016, the sigma convergence of economic growth rates in Russian megacities is present starting from 2013. At the same time, until 2013, the pace of the indicator did not demonstrate a steady trend.

2. The spatial heterogeneity of economic growth rates was revealed by both the Moran and Geary indices as well as indicated by the Moran's scatterplot. A positive spatial clustering of the average growth rate of the city product per capita was found and should be taken into account under empirical studies.

3 . In the case of models of minimal conditional and conditional beta-convergence, estimates of the coefficient of convergence are significant at less than 5\% significance level. In fact, the hypothesis upon the conditional beta-convergence of the economic growth rates of Russian megacities is confirmed.

4. The coefficient of determination of spatial models increased significantly because exogenous control factors were accounted for within the methodology framework of extended production functions. All estimated coefficients were significant at least at the $5 \%$ significance level, i.e. the logarithm of city product per capita in 2010, the logarithm of fixed capital investment per capitain 2010, the logarithm the average retail volume per capitain 2010, the logarithm of the average annual number of employees of enterprises and organizations in 2010, as well as the dummy variable introduced for "federal cities". Note that, obviously, Russian "federal cities" Moscow and St.Petersburg follows their own development trajectory.

5. The models of spatial autoregression turned out to be the most appropriate under information criteria. Accounting for exogenous factors can significantly increase the speed of convergence (from $1.15 \%$ to $6.6 \%$ ) and, accordingly, reduce the period of semi-convergence down to 10 years.

A continuation of the study may want to include consideration of panel spatial models, which would remove the problem of endogeneity of control variables and improve the accuracy of convergence rate estimates and the period of semi-convergence.

\section{References:}

Ahrend, R. 2002. Speed of Reform, Initial Conditions, Political Orientation or What? Explaining Russian Regions' Economic Performance. DELTA Working Paper No 2002-10, Paris.

Anselin, L. 1988. Spatial Econometrics: Methods and Models, Volume 4, Springer. 
Balash, O.S. 2013. Modeling population growth rate in Russian cities: spatial aspects. Statistics and Economics, Vol. 6, 142-146.

Berkowitz, D., DeJong, D.N. 2003. Policy Reform and Growth in Post-Soviet Russia. European Economic Review, Vol. 47, 337-352.

Buccellato, T. 2007. Convergence Across Russian Regions: A Spatial Econometrics. Approach. Centre for the Study of Economic and Social Change in Europe, SSEES, UCL. Economics Working Papers, No. 72. London, UK.

Celbis, M.G., Wong, P.H., Guznajeva, T. 2018. The Eurasian Customs Union and the Economic Geography of Belarus: A panel convergence approach. Maastricht Economic and social Research Institute on Innovation and Technology, July 3.

Fingleton, B. 2003. European Regional Growth. Springer, Berlin.

Gluschenko, K. 2012. Myths about Beta-Convergence. Journal of the New Economic Association, 4(16), 26-44.

Ivanova, V.I. 2013. Regional Convergence of Income: Spatial Analysis. Spatial Economics, $4,110-119$.

Kolomak, E.A. 2010. Interregional Inequality in Russia: Economic and Social Aspects. Spatial Economics, 1, 26-35.

Kolomak, E.A. 2011. Spatial Externalities as a Source of Economic Growth. Regional Research of Russia, 2(1), 114-119.

Krinichanskii, K.V., Bezrukov, A.V., Lavrent'ev, A.S. 2015. Factors of economic development of cities in the region. Regional economics: Theory and practice, 28, 5468.

Lugovoy, O., Dashkeev, V., Mazayev, I., Fomchenko, D., Polyakov, E., Hecht, A. 2007. Analysis of Economic Growth in Regions: Geographical and Institutional Aspect. SSRN Electronic Journal, DOI: 10.2139/ssrn.1268088.

Pulyaevskaya, V.L. 2015. Gross Municipal Product in assessing the level of economic development of the Republic of Sakha (Yakutia). Vestnik NSUEM, 4, 135-144.

Quah, D.T. 1993. Empirical cross-section dynamics in economic growth. European Economic Review, 37(2-3), 426-434.

Royuela, V., Garcia. G.A. 2015. Economic and Social Convergence in Colombia. Regional Studies, 49(2), 219-239.

Solanko, L. 2003. Bank of Finland Institute for Economies in Transition: An empirical note on growth and convergence across Russian regions. BOFIT Discussion Papers, 9.

Solow, R.M. 1956. A Contribution to the Theory of Economic Growth. Quarterly Journal of Economics, 70, 65-94.

Swan, T.W. 1956 Economic Growth and Capital Accumulation. Economic Record, 32, 334361.

Urban Indicators Guideline. 2009. Better Information, Better Cities: Monitoring the Habitat, Agenda and the Millennium Development Goals - Slums Target. United Nations Human Settlements Programme, 47.

Vakulenko, E.S. 2013. Does migration lead to regional convergence in Russia? Vestnik NSUEM, 4, 239-264.

Zverev, D.V., Kolomak, E.A. 2010. Sub-Federal fiscal policy in Russia: interregional differences and connections. Series "Scientific reports: independent economic analysis", No. 214. Moscow public science Foundation, Siberian center for applied economic research, 160. 